\title{
Molecular comparison of pure ovarian fibroma with serous benign ovarian tumours
}

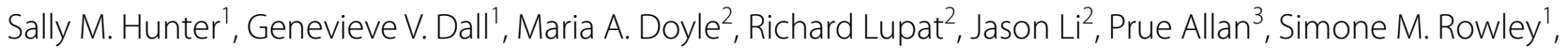 \\ David Bowtell ${ }^{1,4,5}$, On behalf of AOCS, lan G. Campbell ${ }^{1,4,5 \dagger}$ and Kylie L. Gorringe ${ }^{1,4,5,6^{*}+}$ (D)
}

\begin{abstract}
Objective: Ovarian fibromas and adenofibromas are rare ovarian tumours. They are benign tumours composed of spindle-like stromal cells (pure fibroma) or a mixture of fibroblast and epithelial components (adenofibroma). We have previously shown that $40 \%$ of benign serous ovarian tumours are likely primary fibromas due to the neoplastic alterations being restricted to the stromal compartment of these tumours. We further explore this finding by comparing benign serous tumours to pure fibromas.

Results: Performing copy number aberration (CNA) analysis on the stromal component of 45 benign serous tumours and 8 pure fibromas, we have again shown that trisomy of chromosome 12 is the most common aberration in ovarian fibromas. CNAs were more frequent in the pure fibromas than the benign serous tumours (88\% vs 33\%), however pure fibromas more frequently harboured more than one CNA event compared with benign serous tumours. As these extra CNA events observed in the pure fibromas were unique to this subset our data indicates a unique tumour evolution. Gene expression analysis on the two cohorts was unable to show gene expression changes that differed based on tumour subtype. Exome analysis did not reveal any recurrently mutated genes.
\end{abstract}

Keywords: Ovarian fibroma, Adenofibroma, Cystadenomas, Cystadenofibroma, Copy number aberrations, Gene expression, Exome sequencing, Microarrays

\section{Introduction}

Ovarian fibromas and adenofibromas form part of the sex-cord stromal family of tumours and are relatively uncommon, accounting for approximately $8 \%$ of all diagnosed ovarian tumours [1]. These tumours are benign entities composed in significant part of fibroblasts (pure fibromas), or as compound tumours composed of a mix of fibroblast and epithelial (adenofibroma) or sex-cord (granulosa-stromal tumours) components. Tumours with a cystic epithelial component are termed cystadenomas or cystadenofibromas.

\footnotetext{
*Correspondence: kylie.gorringe@petermac.org

${ }^{\dagger}$ Ian G. Campbell and Kylie L. Gorringe contributed equally

${ }^{6}$ Peter MacCallum Cancer Centre, Locked Bag 1, A'Beckett Street,

Melbourne, VIC 8006, Australia

Full list of author information is available at the end of the article
}

Due to their relative rarity and benign nature these tumours have not been well molecularly characterised, with the majority of studies focussing on immunohistochemistry and cytogenetics. Ovarian fibromas differ from fibromas arising in other organs in that they frequently express hormone receptors (e.g. ER- $\beta$, PR, AR) and are typically negative for the characteristic markers of other cells derived from a fibroblast/myofibroblastic origin (e.g. SMA, CD34, CD117, S-100) [1, 2].

Genomic aberrations involving trisomy and tetrasomy of chromosome 12 appear to be particularly prevalent in tumours arising in the female genitourinary tract, including uterine leiomyomas [3, 4], thecomas [5-7], fibromas [7-10] and granulosa cell tumours [11, 12]. The underlying biological driver for this recurrent event has yet to be established. Other genomic aberrations that arise less frequently may be more cell type-specific. Imbalances

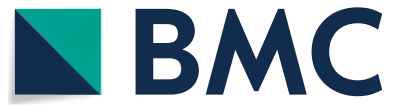

(c) The Author(s) 2020. This article is licensed under a Creative Commons Attribution 4.0 International License, which permits use, sharing, adaptation, distribution and reproduction in any medium or format, as long as you give appropriate credit to the original author(s) and the source, provide a link to the Creative Commons licence, and indicate if changes were made. The images or other third party material in this article are included in the article's Creative Commons licence, unless indicated otherwise in a credit line to the material. If material is not included in the article's Creative Commons licence and your intended use is not permitted by statutory regulation or exceeds the permitted use, you will need to obtain permission directly from the copyright holder. To view a copy of this licence, visit http://creativeco mmons.org/licenses/by/4.0/. The Creative Commons Public Domain Dedication waiver (http://creativecommons.org/publicdomain/ zero/1.0/) applies to the data made available in this article, unless otherwise stated in a credit line to the data. 
involving chromosomes 4 and 9 are also common in the fibroma-thecoma subgroup, with chromosome 9 aberrations potentially being associated with cellular fibromas [13].

We previously reported that around $40 \%$ of benign serous cystadenomas and cystadenofibromas show copy number aberrations (CNA) exclusively in the stroma [14] and are thus likely misdiagnosed primary fibromas with epithelial inclusion. To investigate this further we undertook molecular characterisation of these epithelial-stromal tumours in comparison to pure fibromas.

\section{Main text}

\section{Materials and methods \\ Tissue samples}

Fresh frozen tissue samples were used for copy number, exome and expression analyses. All samples were collected with the patient's informed consent and the study was approved by the Human Research Ethics Committees at the Peter MacCallum Cancer Centre. Patients with ovarian tumors were identified through hospitals in the Wessex Region, UK $(n=25)$ [15] and the Australian Ovarian Cancer Study (AOCS) $(\mathrm{n}=31)[16,17]$. Pathology review was conducted on cryosections adjacent to the tissue from which DNA was extracted (PA). Microdissections and DNA/RNA extractions were performed as previously described [18]. Samples were selected for inclusion based on availability of tissue for DNA and RNA extraction.

\section{Copy number data}

The Affymetrix SNP6.0 Human Mapping (1.8 M probe set) array was utilised for ultra-high resolution allelespecific copy number analysis. Arrays were performed as recommended by the manufacturer with the exception that the input was reduced from the recommended $500 \mathrm{ng}$ to $250 \mathrm{ng}$ by reducing reaction volumes by half for all processes prior to the SNP6.0 PCR step. Reduction in DNA input does not result in any loss in the quality of the data. Copy number analysis was performed as previously described [18], using Partek Genomics Suite v 6.5. Copy number and allele-specific copy number was generated paired (when matching normal available) or unpaired and circular binary segmentation was performed to identify regions of copy number and loss of heterozygosity. Thresholds were $>2.3$ for gains, $<1.7$ for losses and $<0.75$ for homozygous deletions. All SNP data has been made publicly available through Gene Expression Omnibus (http://www.ncbi.nlm.nih.gov/geo/ - GSE67189).

\section{Exome sequencing}

For each case $500 \mathrm{ng}-1 \mu \mathrm{g}$ of microdissected tumour DNA and matched lymphocyte DNA when available was sheared to $<1000$ bp using a Covaris ${ }^{\circledR}$ ultra-sonicator $\left(\right.$ Covaris $\left.^{\circledR}\right)$, libraries prepared using the Illumina TruSeq DNA Sample Preparation procedure (Illumina), and enriched for exome sequencing using the SeqCap EZ Human Exome Library v2.0 (Roche NimbleGen). Exomes were sequenced with $100 \mathrm{bp}$ PE reads in pools of three per lane on a HiSeq 2000 (Illumina).

Sequence reads were aligned to the human genome (GRCh37/hg19) using BWA-MEM (v0.7.7-r441) [19, 20]; duplicates marked using Picard (v1.77); local indel realignment and base quality recalibration performed using GATK (v2.7-2-g6bda569) [21, 22]; indel detection performed using GATK Unified Genotyper (v2.7-2g6bda569), Indel Genotyper, Pindel (v0.2.5a3) [23], and VarScan2 (v2.2.4) [24]; SNV prediction performed using GATK Unified Genotyper, MuTect (v2.7-1-g42d771f) [25], SomaticSniper [26], JointSNVMix2 (v0.8-b2) [27], and VarScan2 (v2.2.4); and variants annotated using Ensembl variant effect predictor v73. Exome bam files are available from the Sequence Read Archive Accession number PRJNA631561 (https://www.ncbi.nlm.nih.gov/ sra/PRJNA631561).

Variants were enriched for genuine somatic events by filtering for those called by $>=2$ variant callers, with the exception of MuTect, which is capable of detecting variants at lower frequencies and therefore all MuTect variants were included; germline allele frequency $<=0.01$ and tumour allele frequency $>=0.05$, with $>=0.1$ difference in allele frequency between tumour and germline; variant observed in $<=3$ of 250 in-house germ-line exomes. All variants with a tumour allele frequency $>=0.1$ were taken forward for Sanger sequencing validation.

\section{Expression data}

Expression data was generated using the Affymetrix Human Gene 1.0 ST array according to the manufacturer's recommendations. An input of $300 \mathrm{ng}$ of total RNA was used, as quantified by Nanodrop spectrophotometer. RIN values were determined using the Agilent Bioanalyzer RNA 6000 Nano assay, the average RIN value for the 25 samples was 4.7 (range 1-7.9). Analysis of the data was performed using the Partek Gene Expression workflow. CEL files were processed using RMA normalisation and batch correction. All Gene 1.0 ST data has been made publicly available through Gene Expression Omnibus (http://www.ncbi.nlm.nih.gov/geo/-GSE67223).

\section{Results}

The clinical features of the ovarian cohort are presented in Table 1. Women with ovarian fibromas compared to benign serous ovarian tumours had very similar median ages and ranges (64, range $35-80$ and 61 , range $27-80$ respectively). Interestingly, there appeared to be a strong 
Table 1 Clinical features of cohort

\begin{tabular}{|c|c|c|c|c|c|}
\hline Sample ID & Age & Laterality & $\mathrm{CN}$ & $\begin{array}{l}\text { Gene } \\
\text { expression }\end{array}$ & Exome \\
\hline \multicolumn{6}{|c|}{ Pure Fibromas } \\
\hline IC33 & 80 & Bilateral (same) & Y & Y & \\
\hline IC4 & $\mathrm{n} / \mathrm{a}$ & Bilateral (same) & Y & Y & \\
\hline IC269 & 59 & Right & Y & Y & \\
\hline IC425 & 49 & Left & Y & Y & \\
\hline IC458 & 35 & Right & Y & Y & \\
\hline IC494 & 53 & Bilateral (same) & $Y$ & Y & \\
\hline $\mathrm{IC} 181$ & 65 & Right & Y & Y & \\
\hline IC137 & 64 & Bilateral (other) & Y & Y & \\
\hline \multicolumn{6}{|c|}{ Cystadenofibroma } \\
\hline IC149 & 66 & Bilateral (same) & Y & Y & \\
\hline $\mathrm{IC} 10$ & 59 & Right & Y & Y & \\
\hline $\mathrm{IC} 164$ & 72 & Left & $Y^{a}$ & Y & Y \\
\hline IC158 & 82 & Bilateral (same) & $Y^{a}$ & Y & Y \\
\hline $\mathrm{IC} 5$ & 81 & Left & $Y^{a}$ & Y & Y \\
\hline IC103 & 56 & Bilateral (same) & $Y^{a}$ & Y & Y \\
\hline IC467 & 52 & Right & $Y^{a}$ & Y & Y \\
\hline $\mathrm{IC} 120$ & 74 & Right & Y & Y & \\
\hline A4 & 74 & Right & $Y^{a}$ & & Y \\
\hline $\mathrm{A} 3$ & 61 & Bilateral (same) & $Y^{a}$ & & Y \\
\hline$A 2$ & 63 & Bilateral (same) & $Y^{a}$ & & Y \\
\hline A5 & 66 & Right & $Y^{a}$ & & Y \\
\hline A6 & 75 & Bilateral (same) & $Y^{a}$ & & \\
\hline A8 & 48 & Bilateral (same) & Y & & \\
\hline A9 & 66 & Left & $Y^{a}$ & & \\
\hline A10 & 54 & Bilateral (same) & $Y^{a}$ & & \\
\hline A25 & 61 & Right & $Y^{a}$ & & \\
\hline A11 & 72 & Bilateral (same) & $Y^{a}$ & & \\
\hline A12 & 76 & Bilateral (same) & $Y^{a}$ & & \\
\hline A61 & 68 & Right & Y & & \\
\hline A29 & 57 & Bilateral (same) & $Y^{a}$ & & \\
\hline $\mathrm{A} 22$ & 51 & Bilateral (same) & $Y^{a}$ & & \\
\hline A13 & 50 & Right & $Y^{a}$ & & \\
\hline A 14 & 62 & Bilateral (same) & $Y^{a}$ & & \\
\hline A15 & 45 & Left & $Y^{a}$ & & \\
\hline A7 & 69 & Right & $Y^{a}$ & & \\
\hline \multicolumn{6}{|c|}{ Adenofibroma } \\
\hline IC450 & 27 & Right (other) & $Y^{a}$ & Y & Y \\
\hline \multicolumn{6}{|c|}{ Cystadenoma } \\
\hline IC 148 & 67 & Bilateral (other) & $Y^{a}$ & Y & Y \\
\hline $\mathrm{IC} 24$ & 77 & Bilateral (same) & Y & Y & \\
\hline IC196 & 46 & unilateral (unspecified) & Y & Y & \\
\hline IC7 & 79 & Right & $Y^{a}$ & Y & \\
\hline IC591 & 48 & Right & Y & Y & \\
\hline A17 & 35 & Bilateral (same) & $Y^{a}$ & & Y \\
\hline A16 & 50 & Right & $Y^{a}$ & & \\
\hline A18 & 73 & Bilateral (same) & $Y^{a}$ & & \\
\hline A19 & 46 & Right & $Y^{a}$ & & \\
\hline A20 & 65 & Right & $Y^{a}$ & & \\
\hline
\end{tabular}

Table 1 (continued)

\begin{tabular}{|c|c|c|c|c|c|}
\hline Sample ID & Age & Laterality & $\mathrm{CN}$ & $\begin{array}{l}\text { Gene } \\
\text { expression }\end{array}$ & Exome \\
\hline A23 & 58 & Bilateral (same) & $Y^{a}$ & & \\
\hline $\mathrm{A} 21$ & 64 & Bilateral (same) & $Y^{a}$ & & \\
\hline A26 & 55 & Bilateral (same) & $Y^{a}$ & & \\
\hline $\mathrm{A} 27$ & 59 & Left & $Y^{a}$ & & \\
\hline A62 & 68 & Bilateral (same) & Y & & \\
\hline A63 & 43 & Right & Y & & \\
\hline A64 & 55 & Bilateral (same) & Y & & \\
\hline $\mathrm{A} 24$ & 58 & Bilateral (same) & $Y^{a}$ & & \\
\hline \multicolumn{6}{|l|}{ Normal } \\
\hline IC79 & 60 & $\mathrm{n} / \mathrm{a}$ & & Y & \\
\hline IC236 & $\mathrm{n} / \mathrm{a}$ & $\mathrm{n} / \mathrm{a}$ & & Y & \\
\hline IC369 & 40 & $\mathrm{n} / \mathrm{a}$ & & Y & \\
\hline
\end{tabular}

preponderance for both fibromas and benign serous tumours to be bilateral or detected on the right ovary (Binomial test for left vs right $\mathrm{P}=0.02$ ).

\section{Copy number aberrations}

Genome-wide copy number analysis was performed for eight unselected pure fibromas, and compared to copy number data from the stroma of 27 serous cystadenofibromas and 18 serous cystadenomas (collectively referred to as benign serous tumours). CNAs were detectable in $7 / 8(88 \%)$ of the pure fibromas, with gain of chromosome 12 being the most recurrently observed aberration in five of eight (63\%) cases (Additional file 1: Table S1). Other recurrent CNAs in the fibromas were gain of chromosomes 9 or 9q (50\% cases), 18 and 21 (20\% cases each). CNAs were detected in the stroma of $33 \%$ of benign serous tumours. Recurrent gain of chromosome 12 was also observed in $31 \%$ of serous cystadenofibromas $(8 / 27)$ and $17 \%$ of serous cystadenomas (3/18), gain of $9 \mathrm{q}$ was only observed in single serous cystadenofibroma case, while loss of chromosome 22 was detected in $11 \%$ of cystadenofibromas (3/27). No CNAs were detected in the stroma of the normal ovaries.

\section{Expression analysis}

Gene expression arrays were used to compare the stromal RNA of three normal ovaries against eight pure fibromas (seven with CNAs), seven cystadenomas (two with CNAs), and seven cystadenofibromas (four with CNAs). Comparing normal ovary to benign serous tumours or fibromas did not identify any differentially expressed genes following multiple testing correction. Comparison of benign serous tumours to fibromas also did not 
identify any differentially expressed genes. Comparison of samples based on the presence or absence of CNA, or the presence of specific CNA compared to an absence of genomic aberrations (with and without tumour subtyping), did not identify differentially expressed genes that remained significant following multiple testing correction. As these samples are difficult to enrich for neoplastic cells due to a mixture of cell types in the stroma the expression signal from the tumour cells will be diluted, therefore a less stringent approach was taken to identify candidate genes by taking the most significantly altered genes $\mathrm{p}<=0.001$ with a fold change $>=2$. Through this approach 17 genes were found to be differentially expressed based on the presence of specific CNA (gain $9 \mathrm{q}$ and 12, loss of 16q) compared to samples with no genomic CNAs (Table 2).

\section{Exome data}

Exome sequencing was performed on the stromal DNA of seven cystadenofibromas, one adenofibroma and one cystadenoma (all with CNAs), and two cystadenofibromas and one cystadenoma with no CNAs. Exome sequencing identified 83 putative somatic variants, with an average of 7 mutations per case (range 2-20). It is difficult to enrich for the subpopulation of neoplastic fibroblasts in the stroma, as indicated by the low variant allele frequency of the majority of the variants (Additional file 2: Table S2), and subsequently difficult to validate findings by Sanger sequencing. We undertook Sanger validation of a subset of variants for each case. No recurrent mutations or recurrently mutated genes were identified that went on to validate. In total, 20 somatic variants were able to be validated by Sanger sequencing (Table 3). Of the validated variants, a single nonsense mutation was identified in the $D M D$ gene. The remaining 19 validated variants were all missense variants, the functional impacts of which were assessed using transFIC (Transformed Functional Impact for Cancer) (Table 3). No variants from the three tumours with no CNAs validated by Sanger sequencing.

The ability to detect variants may be confounded by normal DNA contamination. There was a positive correlation between the number of variants detected (before

Table 2 Candidate genes for differential expression

\begin{tabular}{|c|c|c|c|c|}
\hline Gene & Cytoband & Fold-change & $P$ value & Function \\
\hline \multicolumn{5}{|c|}{ 9q genes gain vs no gain } \\
\hline HAPLN1 & $5 q 14.3$ & +5.2 & 0.000008 & ECM protein and ERK signalling; overexpressed in metastatic melanoma and mesotheliomas \\
\hline PRAME & $22 q 11.22$ & +3.6 & 0.000342 & Repressor of retinoic acid receptor. Overexpressed in multiple neoplasms (including melanoma) \\
\hline SLC17A3 & $6 \mathrm{p} 22.2$ & +3.3 & 0.000081 & Voltage-driven transporter. Affects serum uric acid levels \\
\hline CKS2 & $9 q 22.2$ & +3.3 & 0.000232 & $\begin{array}{l}\text { CDC28 protein kinase regulatory subunit 2. Overexpressed in numerous neoplasms, overrides the } \\
\text { intra-S-phase DNA damage checkpoint }\end{array}$ \\
\hline ANOS1 & Xp22.31 & +2.8 & 0.000297 & ECM protein. Putative cell adhesion molecule, upregulated in some tumour types \\
\hline RNF182 & $6 \mathrm{p} 23$ & +2.5 & 0.000110 & E3 ubiquitin ligase. Overexpressed in Alzheimers \\
\hline SLC17A1 & $6 \mathrm{p} 22.2$ & +2.3 & 0.000711 & Sodium-dependent phosphate transporter. Affects uric acid levels \\
\hline CRB1 & $1 \mathrm{q} 31.3$ & +2.1 & 0.000466 & Photoreceptor protein \\
\hline SYT14 & $1 \mathrm{q} 32.2$ & +2.1 & 0.000601 & Family of proteins involved in synaptic transmission \\
\hline C6orf115 & $6 q 24.1$ & +2 & 0.000848 & Uncharacterised protein \\
\hline$A P O D$ & $3 q 29$ & -2.6 & 0.000762 & $\begin{array}{l}\text { Putative lipoprotein metabolism. Inverse correlation between expression and colorectal tumour } \\
\text { progression. Associated with neurodegeneration }\end{array}$ \\
\hline$C L U$ & $8 p 21.1$ & -2.4 & 0.000751 & $\begin{array}{l}\text { Secreted anti-apoptotic chaperone protein. Overexpressed in many tumour types and associated } \\
\text { with neurodegeneration }\end{array}$ \\
\hline SLFN11 & $17 q 12$ & -2.3 & 0.000237 & $\begin{array}{l}\text { Putative DNA/RNA helicase. Expression of other family members inhibits growth of fibroblasts and } \\
\text { thymoctyes. Sensitises cancer cells to DNA damaging agents }\end{array}$ \\
\hline \multicolumn{5}{|c|}{ chr12 genes gain vs no gain } \\
\hline NDST3 & $4 q 26$ & +2.9 & 0.000814 & $\begin{array}{l}\text { N-deacetylase/N-sulfotransferase 3. Golgi apparatus protein, associated with schizophrenia and } \\
\text { bipolar disorder }\end{array}$ \\
\hline PRELP & $1 \mathrm{q} 32.1$ & -2.2 & 0.000646 & Connective tissue ECM protein. Abnormally expressed in chronic lymphocytic leukaemia cells \\
\hline \multicolumn{5}{|c|}{$16 q$ genes loss vs no loss } \\
\hline PRAME & $22 q 11.22$ & +6.4 & 0.000347 & Repressor of retinoic acid receptor. Overexpressed in multiple neoplasms (including melanoma). \\
\hline GLRA2 & $\mathrm{xp} 22.2$ & +2.7 & 0.000412 & Glycine receptor alpha 2, neutrophil and p38 MAPK associated \\
\hline GABRA5 & $15 q 12$ & +2.5 & 0.000136 & GABA receptor alpha 5, associated with schizophrenia and bipolar I disorder \\
\hline SLFN11 & $17 q 12$ & -3.6 & 0.000336 & $\begin{array}{l}\text { Putative DNA/RNA helicase. Expression of other family members inhibits growth of fibroblasts and } \\
\text { thymoctyes. Sensitises cancer cells to DNA damaging agents }\end{array}$ \\
\hline
\end{tabular}




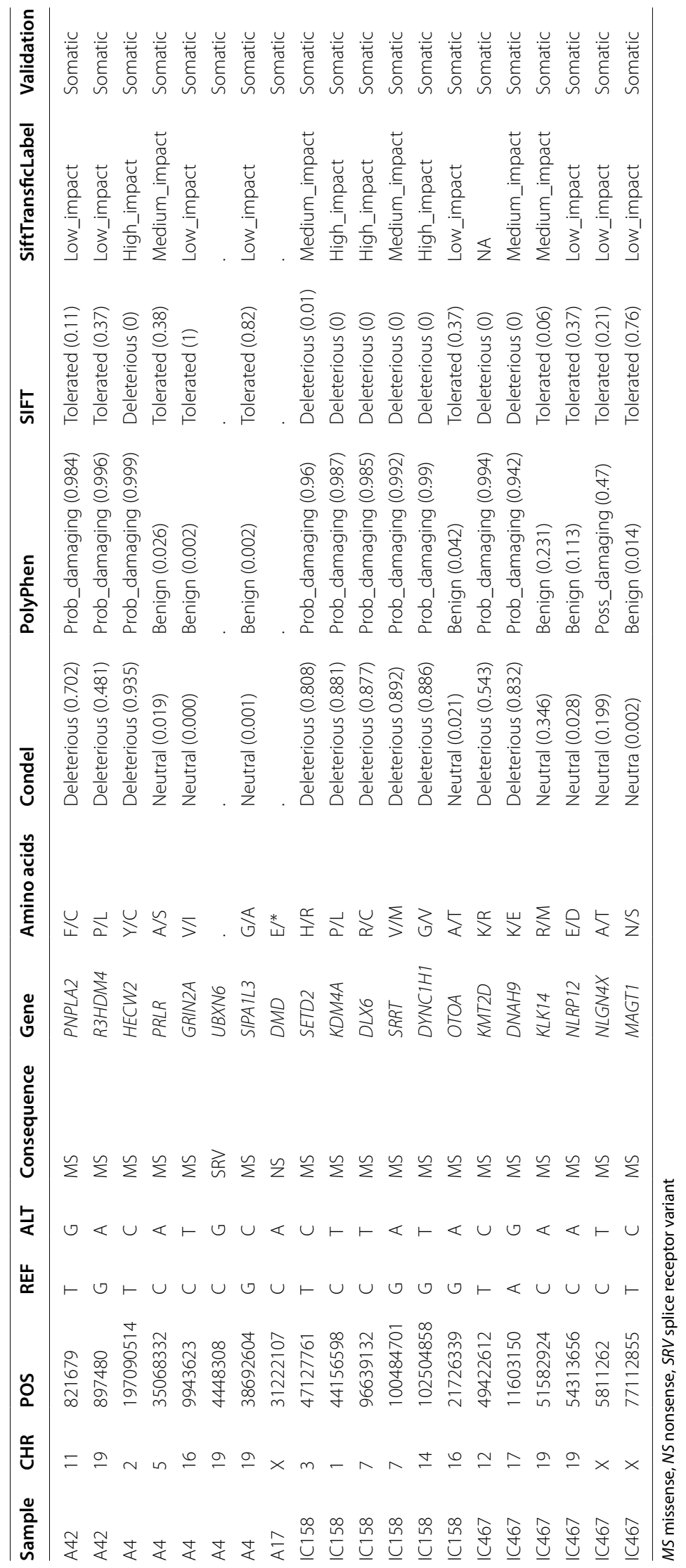


validation) and the average allele frequency (Spearman's $\mathrm{r}=0.76, \mathrm{P}=0.01$, Additional file 3: Figure S1). The mean sequencing depth was 121.3 reads $(88.6-186.8)$ for germline samples and 122.7 reads (72.8-163.6) for somatic samples, therefore the detection of low frequency variants is not substantially compromised by limited depth of coverage.

\section{Discussion}

The findings of this study are consistent with previous karyotyping and FISH studies that identified trisomy 12 as the most common chromosomal abnormality identifiable in ovarian fibromas [8-10]. Pure ovarian fibromas were found to harbour chromosomal abnormalities more frequently than benign serous ovarian tumours $(88 \%$ vs. 33\%), further supporting our hypothesis that a subset of benign serous tumours are actually fibromas that coincidentally have an associated epithelial cyst. However, benign serous tumours more frequently harboured trisomy 12 as the sole aberration (47\% of tumours with aberrations) compared to fibromas (30\% of tumours with aberrations). Fibromas also more frequently harboured CNA that were rarely detected in the benign serous tumours such as $9 \mathrm{q}$ gain (50\% cases), potentially indicating unique underlying biological drivers.

Expression analysis provided some interesting candidates that have previously been associated with neoplasms or fibroblast growth for further investigation. Genes with increased expression in tumours with CNAs compared to those without CNAs included the extracellular matrix (ECM) and signalling molecules HAPLN1 and $A N O S 1$, the antigen and repressor of retinoic acid signalling molecule $P R A M E$, and the cell cycle regulator CKS2. All of these genes have been previously associated with overexpression in other types of neoplasm [28-34], and PRAME and CKS2 expression have been proposed as markers of poor prognosis in high-grade serous ovarian carcinoma [33, 35].

Genes with decreased expression in tumours with CNAs compared to those without CNAs included the putative DNA/RNA helicase SLFN11, the ECM protein $P R E L P$, the high density lipoprotein component $A P O D$, and the secreted chaperone $C L U$. Although these have all been linked with altered expression in other neoplasms before, this has typically been upregulation and potentially linked to neoplastic progression [36-40], including in ovarian cancer for APOD and CLU [41, 42]. Data is inconsistent for $C L U$, as expression was also linked to improved prognosis in high-grade serous ovarian carcinoma [33]. Low expression of SLFN11 has been associated with resistance to chemotherapy in ovarian cancer other cancers due to its role in the DNA damage response [43].
No genes were found to be recurrently mutated, however, two tumours had mutations in histone methytransferases (SETD2 and KMT2D) and one also had a mutation in a demethylase (KDM4A), all previously associated with neoplasia and all mutations predicted to be deleterious. Other mutated genes have also been associated with neoplasia, such as $H E C W 2, S R R T$ and $K L K 14$, with predicted medium to high deleterious impact.

\section{Limitations}

- Use of Affymetrix Human Gene 1.0 ST array is limited to the probes on the array at the time.

- Insufficient power to detect differentially expressed genes due to $\mathrm{n}=3$ normal ovaries.

- Limited ability to detect mutations due to normal contamination.

\section{Supplementary information}

Supplementary information accompanies this paper at https://doi. org/10.1186/s13104-020-05194-z.

Additional file 1: Table S1. Genomic copy number aberrations.

Additional file 2: Table S2. Variants detected by exome sequencing.

Additional file 3: Figure S1. Correlation between the number of mutations and average allele frequency, suggesting that normal contamination may limit the number of mutations detected.

\section{Acknowledgements}

The AOCS acknowledges the cooperation of the participating institutions in Australia and acknowledges the contribution of the study nurses, research assistants and all clinical and scientific collaborators to the study. The complete AOCS Study Group can be found at www.aocstudy.org. We would like to thank all of the women who participated in these research programs.

\section{Authors' contributions}

Study design: KLG and IGC; Experiments: SMH and SMR; Data analysis: SMH, GVD, KLG, MAD, RL, JL; Preparation of tables and figures: KLG, GVD, SMH; Pathology review: PA; Collection of samples: DDLB; Drafting of manuscript: SMH, GVD, KLG and IGC. All authors reviewed and revised the manuscript. All authors read and approved the final manuscript.

\section{Funding}

This study was supported by the Victorian Breast Cancer Research Consortium (VBCRC) and the National Health \& Medical Research Council of Australia (NHMRC, ID 628630) and the Emer Casey Foundation. The Australian Ovarian Cancer Study Group was supported by the U.S. Army Medical Research and Materiel Command under DAMD17-01-1-0729, The Cancer Council Victoria, Queensland Cancer Fund, The Cancer Council New South Wales, The Cancer Council South Australia, The Cancer Council Tasmania and The Cancer Foundation of Western Australia (Multi-State Applications 191, 211 and 182) and the National Health and Medical Research Council of Australia (NHMRC; ID400413 and ID400281). The Australian Ovarian Cancer Study gratefully acknowledges additional support from Ovarian Cancer Australia and the Peter MacCallum Foundation.

\section{Availability of data and materials}

Gene Expression Omnibus GSE67189-Molecular characterization of ovarian serous cystadenomas and fibromas [Copy number], GSE67223-Molecular characterization of ovarian serous cystadenomas and fibromas [Expression], 
GSE67224-Molecular characterization of ovarian serous cystadenomas and fibromas Sequence Read Archive PRJNA631561 (https://www.ncbi.nlm.nih. gov/sra/PRJNA631561).

\section{Ethics approval and consent to participate}

This study was conducted in accordance with the Declaration of Helsinki. All samples were collected with the patient's written informed consent and the study was approved by the Human Research Ethics Committees at the Peter MacCallum Cancer Centre.

\section{Consent for publication}

Not applicable.

\section{Competing interests}

The authors declare no competing interests.

\section{Author details}

${ }^{1}$ Cancer Genomics Program, Peter MacCallum Cancer Centre, East Melbourne, Australia. ${ }^{2}$ Bioinformatics Core Facility Peter MacCallum Cancer Centre, East Melbourne, Victoria, Australia. ${ }^{3}$ Anatomical Pathology, Peter MacCallum Cancer Centre, East Melbourne, Victoria, Australia. ${ }^{4}$ The Department of Pathology, University of Melbourne, Parkville, Australia. ${ }^{5}$ The Sir Peter MacCallum Department of Oncology, University of Melbourne, Parkville, Australia. ${ }^{6}$ Peter MacCallum Cancer Centre, Locked Bag 1, A'Beckett Street, Melbourne, VIC 8006, Australia.

Received: 1 June 2020 Accepted: 17 July 2020

Published online: 22 July 2020

\section{References}

1. He H, Luthringer DJ, Hui P, Lau SK, Weiss LM, Chu PG. Expression of CD56 and WT1 in ovarian stroma and ovarian stromal tumors. Am J Surgical Pathol. 2008;32(6):884-90.

2. Deavers MT, Malpica A, Liu J, Broaddus R, Silva EG: Ovarian sex cordstromal tumors: an immunohistochemical study including a comparison of calretinin and inhibin. Modern pathology: an official journal of the United States and Canadian Academy of Pathology, Inc 2003, 16(6):584-590.

3. Kiechle-Schwarz M, Pfleiderer A, Sreekantaiah C, Berger CS, Medchill MT, Sandberg AA. Cluster of trisomy 12 to tumors of the female genitourinary tract. Cancer Genet Cytogenet. 1991;54(2):273-5.

4. Pandis N, Heim S, Bardi G, Floderus UM, Willen H, Mandahl N, Mitelman F. Chromosome analysis of 96 uterine leiomyomas. Cancer Genet Cytogenet. 1991;55(1):11-8.

5. Dal Cin P, Moerman P, De Wever I, Van den Berghe H. Numerical chromosome aberrations in fibrothecoma. Tumori. 1992;78(2):140-2.

6. Izutsu T, Kudo T, Miura F, Nishiya I. Numerical and structural chromosome abnormalities in an ovarian fibrothecoma. Cancer Genet Cytogenet. 1995:83(1):84-6.

7. Micci F, Haugom L, Abeler VM, Trope CG, Danielsen HE, Heim S. Consistent numerical chromosome aberrations in thecofibromas of the ovary. Virchows Arch. 2008;452(3):269-76.

8. Leung WY, Schwartz PE, Ng HT, Yang-Feng TL. Trisomy 12 in benign fibroma and granulosa cell tumor of the ovary. Gynecol Oncol. 1990;38(1):28-31.

9. Liang SB, Sonobe H, Taguchi T, Takeuchi T, Furihata M, Yuri K, Ohtsuki Y. Tetrasomy 12 in ovarian tumors of thecoma-fibroma group: a fluorescence in situ hybridization analysis using paraffin sections. Pathol Int. 2001;51(1):37-42.

10. Persons DL, Hartmann LC, Herath JF, Keeney GL, Jenkins RB. Fluorescence in situ hybridization analysis of trisomy 12 in ovarian tumors. Am J Clin Pathol. 1994;102(6):775-9.

11. Fletcher JA, Gibas Z, Donovan K, Perez-Atayde A, Genest D, Morton CC, Lage JM. Ovarian granulosa-stromal cell tumors are characterized by trisomy 12. Am J Pathol. 1991;138(3):515-20.

12. Schofield DE, Fletcher JA. Trisomy 12 in pediatric granulosa-stromal cell tumors. Demonstration by a modified method of fluorescence in situ hybridization on paraffin-embedded material. Am J Pathol. 1992;141(6):1265-9.
13. Streblow RC, Dafferner AJ, Nelson M, Fletcher M, West WW, Stevens RK, Gatalica Z, Novak D, Bridge JA. Imbalances of chromosomes 4, 9, and 12 are recurrent in the thecoma-fibroma group of ovarian stromal tumors. Cancer Genet Cytogenet. 2007;178(2):135-40.

14. Hunter SM, Anglesio MS, Sharma R, Gilks CB, Melnyk N, Chiew YE, deFazio A, Australian Ovarian Cancer Study G, Longacre TA, Huntsman DG, et al. Copy number aberrations in benign serous ovarian tumors: a case for reclassification. Clin Cancer Res. 2011;17(23):7273-82.

15. Bryan EJ, Watson RH, Davis M, Hitchcock A, Foulkes WD, Campbell IG. Localization of an ovarian cancer tumor suppressor gene to a 0.5-cM region between D22S284 and CYP2D, on chromosome 22q. Cancer Res. 1996;56(4):719-21.

16. Anglesio MS, Arnold JM, George J, Tinker AV, Tothill R, Waddell N, Simms L, Locandro B, Fereday S, Traficante N, et al. Mutation of ERBB2 provides a novel alternative mechanism for the ubiquitous activation of RAS-MAPK in ovarian serous low malignant potential tumors. Mol Cancer Res. 2008;6(11):1678-90.

17. Tothill RW, Tinker AV, George J, Brown R, Fox SB, Lade S, Johnson DS, Trivett MK, Etemadmoghadam D, Locandro B, et al. Novel molecular subtypes of serous and endometrioid ovarian cancer linked to clinical outcome. Clin Cancer Res. 2008;14(16):5198-208.

18. Hunter SM, Gorringe KL, Christie M, Rowley SM, Bowtell DD. Australian Ovarian Cancer Study G, Campbell IG: pre-invasive ovarian mucinous tumors are characterized by CDKN2A and RAS pathway aberrations. Clin Cancer Res. 2012;18(19):5267-77.

19. Li H, Durbin R. Fast and accurate long-read alignment with BurrowsWheeler transform. Bioinformatics. 2010;26(5):589-95.

20. Li H: Aligning sequence reads, clone sequences and assembly contigs with BWA-MEM. Quantitative Biology - Genomics 2013.

21. McKenna A, Hanna M, Banks E, Sivachenko A, Cibulskis K, Kernytsky A, Garimella K, Altshuler D, Gabriel S, Daly M, et al. The Genome Analysis Toolkit: a MapReduce framework for analyzing next-generation DNA sequencing data. Genome Res. 2010;20(9):1297-303.

22. Van der Auwera GA, Carneiro MO, Hartl C, Poplin R, del Angel G, LevyMoonshine A, Jordan T, Shakir K, Roazen D, Thibault J et al: From FastQ Data to High-Confidence Variant Calls: The Genome Analysis Toolkit Best Practices Pipeline. In: Current Protocols in Bioinformatics. John Wiley \& Sons, Inc.; 2002.

23. Ye K, Schulz MH, Long Q, Apweiler R, Ning Z. Pindel: a pattern growth approach to detect break points of large deletions and medium sized insertions from paired-end short reads. Bioinformatics. 2009:25(21):2865-71.

24. Koboldt DC, Zhang Q, Larson DE, Shen D, McLellan MD, Lin L, Miller CA, Mardis ER, Ding L, Wilson RK. VarScan 2: somatic mutation and copy number alteration discovery in cancer by exome sequencing. Genome Res. 2012:22(3):568-76.

25. Cibulskis K, Lawrence MS, Carter SL, Sivachenko A, Jaffe D, Sougnez C, Gabriel S, Meyerson M, Lander ES, Getz G. Sensitive detection of somatic point mutations in impure and heterogeneous cancer samples. Nat Biotechnol. 2013;31(3):213-9.

26. Larson DE, Harris CC, Chen K, Koboldt DC, Abbott TE, Dooling DJ, Ley TJ, Mardis ER, Wilson RK, Ding L. SomaticSniper: identification of somatic point mutations in whole genome sequencing data. Bioinformatics. 2012;28(3):311-7.

27. Roth A, Ding J, Morin R, Crisan A, Ha G, Giuliany R, Bashashati A, Hirst M, Turashvili G, Oloumi A, et al. JointSNVMix: a probabilistic model for accurate detection of somatic mutations in normal/tumour paired nextgeneration sequencing data. Bioinformatics. 2012;28(7):907-13.

28. Lan Y, Zhang Y, Wang J, Lin C, Ittmann MM, Wang F. Aberrant expression of Cks1 and Cks2 contributes to prostate tumorigenesis by promoting proliferation and inhibiting programmed cell death. Int J Cancer. 2008;123(3):543-51.

29. Kang MA, Kim JT, Kim JH, Kim SY, Kim YH, Yeom YI, Lee Y, Lee HG. Upregulation of the cycline kinase subunit CKS2 increases cell proliferation rate in gastric cancer. J Cancer Res Clin Oncol. 2009;135(6):761-9.

30. Shen DY, Fang ZX, You P, Liu PG, Wang F, Huang CL, Yao XB, Chen ZX, Zhang ZY. Clinical significance and expression of cyclin kinase subunits 1 and 2 in hepatocellular carcinoma. Liver Int. 2010;30(1):119-25.

31. Bullinger L, Schlenk RF, Gotz M, Botzenhardt U, Hofmann S, Russ AC, Babiak A, Zhang L, Schneider V, Dohner K, et al. PRAME-induced inhibition of retinoic acid receptor signaling-mediated differentiation-a 
possible target for ATRA response in AML without t(15;17). Clin Cancer Res. 2013;19(9):2562-71.

32. Doolan P, Clynes M, Kennedy S, Mehta JP, Crown J, O'Driscoll L. Prevalence and prognostic and predictive relevance of PRAME in breast cancer. Breast Cancer Res Treat. 2008;109(2):359-65.

33. Partheen K, Levan K, Osterberg L, Claesson I, Fallenius G, Sundfeldt K, Horvath $\mathrm{G}$. Four potential biomarkers as prognostic factors in stage III serous ovarian adenocarcinomas. Int J Cancer. 2008;123(9):2130-7.

34. Haqq C, Nosrati M, Sudilovsky D, Crothers J, Khodabakhsh D, Pulliam BL, Federman S, Miller JR 3rd, Allen RE, Singer MI, et al. The gene expression signatures of melanoma progression. Proc Natl Acad Sci U S A. 2005;102(17):6092-7.

35. $\mathrm{Xu} J \mathrm{~J}$, Wang $Y, X u \mathrm{D}$. CKS2 promotes tumor progression and metastasis and is an independent predictor of poor prognosis in epithelial ovarian cancer. Eur Rev Med Pharmacol Sci. 2019;23(8):3225-34.

36. Wang X, Luo L, Dong D, Yu Q, Zhao K. Clusterin plays an important role in clear renal cell cancer metastasis. Urol Int. 2014;92(1):95-103.

37. Fu Y, Lai Y, Wang Q, Liu X, He W, Zhang H, Fan C, Yang G. Overexpression of clusterin promotes angiogenesis via the vascular endothelial growth factor in primary ovarian cancer. Mol Med Rep. 2013;7(6):1726-32.

38. Sandim V, Pereira Dde A, Kalume DE, Oliveira-Carvalho AL, Ornellas AA, Soares MR, Alves G, Zingali RB. Proteomic analysis reveals differentially secreted proteins in the urine from patients with clear cell renal cell carcinoma. Urol Oncol. 2016;34(1):5 e11-25.
39. Murai J, Thomas A, Miettinen M, Pommier Y. Schlafen 11 (SLFN1 1), a restriction factor for replicative stress induced by DNA-targeting anticancer therapies. Pharmacol Ther. 2019;201:94-102.

40. Mikaelsson E, Osterborg A, Jeddi-Tehrani M, Kokhaei P, Ostadkarampour M, Hadavi R, Gholamin M, Akhondi M, Shokri F, Rabbani H, et al. A proline/arginine-rich end leucine-rich repeat protein (PRELP) variant is uniquely expressed in chronic lymphocytic leukemia cells. PLoS ONE. 2013;8(6):e67601.

41. Vazquez J, Gonzalez L, Merino A, Vizoso F. Expression and clinical significance of apolipoprotein D in epithelial ovarian carcinomas. Gynecol Oncol. 2000;76(3):340-7.

42. Hassan MK, Watari H, Han Y, Mitamura T, Hosaka M, Wang L, Tanaka S, Sakuragi N. Clusterin is a potential molecular predictor for ovarian cancer patient's survival: targeting clusterin improves response to paclitaxel. J Exp Clin Cancer Res. 2011;30:113.

43. Ballestrero A, Bedognetti D, Ferraioli D, Franceschelli P, Labidi-Galy SI, Leo E, Murai J, Pommier Y, Tsantoulis P, Vellone VG, et al. Report on the first SLFN11 monothematic workshop: from function to role as a biomarker in cancer. J Transl Med. 2017;15(1):199.

\section{Publisher's Note}

Springer Nature remains neutral with regard to jurisdictional claims in published maps and institutional affiliations.
Ready to submit your research? Choose BMC and benefit from:

- fast, convenient online submission

- thorough peer review by experienced researchers in your field

- rapid publication on acceptance

- support for research data, including large and complex data types

- gold Open Access which fosters wider collaboration and increased citations

- maximum visibility for your research: over 100M website views per year

At BMC, research is always in progress.

Learn more biomedcentral.com/submissions 